\title{
Graphite reinforced polyvinylidene fluoride composite an efficient and sustainable solution for electromagnetic pollution
}

\author{
Nina Joseph ${ }^{\mathrm{a}, \mathrm{b}}$, Jobin Varghese ${ }^{\mathrm{a}, \mathrm{b}}$ and Mailadil Thomas Sebastian ${ }^{\mathrm{a}, \mathrm{c} *}$ \\ ${ }^{a}$ Materials Science and Technology Division, CSIR-National Institute for interdisciplinary \\ Science and Technology (NIIST), Thiruvananthapuram 695019, Kerala, India. \\ ${ }^{b}$ Microeoectronics Research Unit, Faculty of Information Technology and Electrical \\ Engineering, University of Oulu, 90014 Oulu, Finland \\ ${ }^{c}$ Korean Institute of Ceramic Engineering and Technology (KICET), 101, Jinju-si, \\ Gyeongsangnam-do, South Korea \\ E-mail: mailadils@yahoo.com
}

\begin{abstract}
Graphite flakes reinforced polyvinylidene fluoride (PVDF) composites were prepared and investigated the influence of DC (Direct Current), AC (Alternating Current) conductivity, sample thickness as well as presence of conductive layer on its electromagnetic interference (EMI) shielding effect. The graphite incorporated PVDF composites with sample a thickness of $1 \mathrm{~mm}$ exhibit good shielding properties of about $45-55 \mathrm{~dB}$ in the frequency range of $8.2-18 \mathrm{GHz}$ for highest filler loading. These composites exhibit absorption as the primary mechanism for EMI shielding. Addition of graphite decreases the coefficient of thermal expansion (CTE) and improve the mechanical properties. The EMI shielding effect improved with increase in sample thickness and by incorporating a conductive layer to the graphite flake composite. The graphite flake based composites are found to be lightweight, thin and good EMI shielding materials that can be tuned to wide range of shielding applications.
\end{abstract}

\section{Introduction}

Recently electromagnetic interference shielding materials are attaining considerable interest for protecting environment and sensitive devices from electromagnetic interference (EMI). This problem mainly arises due to the increase in use of high operating frequency and bandwidth in electronic systems especially in the X, Ku band range and broadband frequencies. Hence, EMI shielding materials find application in today's civilian and military technology $[1,2,3]$. 
Conventionally, metals and metallic composites are widely used as effective materials for shielding applications. The metal-based composites are heavier and prone to corrosion, whereas polymer composites are lightweight with design flexibility and ease of processing [2-7]. They have good EMI shielding performance and hence are promising material as alternative to metals for EMI protection. Recently, the EMI shielding capabilities of polymeric materials filled with carbon based materials such as carbon nanotubes, carbon black, graphite flakes, carbon nanofibers and graphene have been investigated since they provide unique combination of conductivity of the filler and flexibility of the polymer [8-20]. Carbon based materials have attracted most attention for effective and practical EMI shielding applications especially in areas of aerospace, automobiles and next generation flexible electronics due to their unique properties [21-26]. Carbon nanotubes currently dominate the composites employing carbon-based reinforced materials. However, the fabrication and application of carbon nanotubes reinforced composites has been limited due to the impurity from catalysts, high costs and difficulties in dispersion in the polymer matrix because of the inherent bundling.

Graphite flakes that consist of parallel carbon layers are extensively studied and are easily available low cost conductors. In addition to the above properties, the ease of preparation by simple solution process make graphite ideal candidates for developing functional and structural composites $[1,9,27]$. The polyaniline- $30 \mathrm{wt} \%$ graphite composite show EMI SE of $33 \mathrm{~dB}$ in the $\mathrm{X}$ band frequency range [11]. It is difficult to compare the shielding performance of composites based on literature data as the EMI shielding performance of composites depend on many factors such as sample thickness, multilayer or hybrid structures, frequency of measurement carried out, polymer matrix type, fabrication and processing conditions. Fundamental understanding of these parameters is very important to achieve the optimum EMI shielding properties. Polyvinylidene fluoride (PVDF) is a well-known ferroelectric polymer material with good chemical resistance, low density and physical flexibility $[2,27,28]$. In the present investigation, graphite flakes (Gp) were added in different volume percentages into the PVDF matrix and the EMI shielding effectiveness of both the composites are measured. The thickness of the highest filler loaded PVDF-graphite flake composite was varied to investigate the effect of shielding thickness on the shielding properties. The influence of $\mathrm{Cu}$ and Pt metallic coating as well as PVDF-30 vol\% of nano $\mathrm{Ag}$ (PVDF-30 nAg) composite layer of varying thickness $(0.1,0.5,1 \mathrm{~mm})$ on the EMI 
shielding efficiency of PVDF-graphite flake composite at a filler loading of 70 vol \% were also investigated.

\section{Experimental}

\subsection{Materials}

The graphite flakes $(\mathrm{Gp})$ used in the present study having density of $2.4 \mathrm{~g} / \mathrm{cm}^{3}$ was bought from Carborundum Universal Ltd, Mumbai, India. The PVDF was provided by Nikunj Industries, Mumbai, India and nano silver (nAg) of about $20 \mathrm{~nm}$ in particle size used in the preparation of PVDF-nano Ag (PVDF-nAg) composites was procured from Aldrich, Chemical Company, Inc., Milwaukee, WI, USA. The dimethyl formamide (DMF) used in the composite preparation was supplied by High Purity Laboratory Chemicals, Mumbai, India.

\subsection{Composite preparation}

All the PVDF based composites were prepared by solution processing according to the following procedure. PVDF was dissolved in DMF and the fillers in the required volume percentage (vol\%) of the final composite were dispersed in the DMF by ultrasonication for $10 \mathrm{~min}$. The dispersed graphite flakes were added to the PVDF solution and the mixture was sonicated for 30 min. The mixture was casted on glass dish and placed in an oven at $60-70{ }^{\circ} \mathrm{C}$ to remove the solvent completely. The resulting mixture was hot pressed at $200{ }^{\circ} \mathrm{C}$ under a pressure of $50 \mathrm{MPa}$ for 30 minutes into samples of different dimensions according to the measurement requirements. The conductivity and EMI SE were measured using samples of dimensions $22.86 \times 10.80 \times 1.00$ and $15.80 \times 7.90 \times 1.00 \mathrm{~mm}$ for $\mathrm{X}$ band $(8.2-12.4 \mathrm{GHz})$ and $\mathrm{Ku}$ band $(12.4-18 \mathrm{GHz})$ frequency range respectively. Coefficient of thermal expansion (CTE) measurement was achieved using cylindrical samples of dimension $10 \times 10 \mathrm{~mm}$. Tensile measurement was performed using dumbbell shaped samples of width $4 \mathrm{~mm}$ and thickness $1.5-2 \mathrm{~mm}$. The DC conductivity was measured using, samples of dimension $22.86 \times 10.80 \times 1.00 \mathrm{~mm}$. The maximum filler loading in the composite depend on the density of the filler incorporated. A filler loading of $70 \mathrm{vol} \%$ was achieved for PVDF-graphite flake (PVDF-Gp) composite. Maximum attained filler loading was 30 vol\% for PVDF-nano Ag composite. The effect of the conducting layer was studied by coating $\mathrm{Cu}$ and Pt metal of about $10 \mathrm{~nm}$ thicknesses on $1 \mathrm{~mm}$ thick PVDF-70 Gp composite by 
vacuum metallization technique. Another approach was by hot pressing PVDF-30 nAg composite of different thickness $(0.1,0.5$ and $1 \mathrm{~mm})$ over $1 \mathrm{~mm}$ thick PVDF-70 Gp composite.

\subsection{Characterization}

The samples were characterized by X-ray diffraction (XRD) using $\mathrm{CuK} \alpha$ radiation (X'Pert PRO MPD X-ray diffractometer, PANalytical, Almelo, Netherlands). Transmission Electron Microscope (TEM) (FEI Tecnai-G2 30S-TWIN, FEI Company, Hillsboro, OR) was employed to characterize the dispersed graphite flakes while the morphology of the samples was analyzed using Scanning Electron Microscope (SEM) (JEOL, JSM-5600LV, Tokyo, Japan). The DC conductivity of the samples was measured using four probe method using current source Aplab $9710 \mathrm{P}$ and nano voltmeter Keithley 2182 A. For standard four probe measurements, the thickness of the sample should be five times greater than the probe tip spacing and the length should be greater to accommodate all the four probe points. Thermo Mechanical Analyser (SII Nanotechnology Inc., Tokyo, Japan, maximum sample dimension of 10 (diameter) $\times 25$ (length) $\mathrm{mm}$ ) measures the coefficient of thermal expansion (CTE) of PVDF-Gp composites. The tensile properties of the samples measured using Universal Testing Machine (Hounsfield, H5K-S UTM, Redhill, UK) at a crosshead speed of $50.0 \mathrm{~mm} \mathrm{~min}^{-1}$ according to ASTM D638 standard. The EMI shielding effectiveness were calculated from the magnitude of complex scattering parameters $S_{11}$ and $S_{21}$ using vector network analyzer (Agilent Technologies E5071C, ENA series, $300 \mathrm{kHz}-20 \mathrm{GHz}, \mathrm{CA}$ ) by the wave guide technique in the frequency range of 8.4-18 GHz using wave guides WR-90 and WR-62 (Agilent Technologies, CA). The complex permittivity was determined from the measured scattering parameters with an accuracy of about $2 \%$ using Agilent software module 85071E. For two-port measurement using wave-guides, the sample has to fit perfectly the entire cross section of the wave-guide transmission line. For complex

permittivity measurements, the thickness of the sample must be less $\operatorname{than} \frac{\lambda}{4}$. Auto fine coater Unit, JEOL, Japan was used for metal coating over PVDF-Gp composite.

\section{Results and discussions}

\subsection{Structure and morphology}


The X-ray diffraction pattern of hot pressed PVDF film, PVDF-Gp composite, and graphite flake powder are shown in figure 1 . The XRD pattern of PVDF shows a low intensity peak at $2 \theta=18.4^{\circ}$ and this corresponds to (020) plane of $\alpha$ phase and a high intensity peak at $20.5^{\circ}$ which corresponds to the (200) and (100) plane of $\beta$ phase. Thus the dominance of the ferroelectric $\beta$ phase in the hot pressed PVDF is evident from the XRD pattern of PVDF [28]. A high intensity diffraction peak at $2 \theta=26.5^{\circ}$ due to the reflection from (002) plane of graphite is observed for PVDF-Gp composite [27, 29]. When graphite flakes are added into PVDF matrix, additional peak at $2 \theta=26.5^{\circ}$ is observed besides the peaks of PVDF and this confirms the presence of that phase in the PVDF matrix (figure 1). The XRD spectra of these composites ruled out the formation of any chemical linkage between PVDF matrix and fillers.

The TEM images of dispersed graphite flake fillers are depicted in the figure 2 (a). It is clear from the TEM images that the filler has flake like morphology and is further confirmed from the SEM image as shown in figure 2 (b). The flake or platelet like structure is reported to be beneficial for good shielding properties $[9,12]$. In such structures, the microwaves undergo multiple reflections from the dihedral angles formed within stacks of flakes. This multiple reflections lead to higher losses of electromagnetic energy due to the interaction of microwaves with materials causing molecular motions such as ionic conduction, dipolar relaxation etc. that are restricted by resistive forces resulting in the dissipation of energy in the form of heat $[9,12]$. SEM images of the fractogram of the PVDF-70 Gp composite shown in figure 2 (c) clearly depicts the uniform dispersion of the fillers in the PVDF matrix even at high filler loading.

\subsection{Thermal and mechanical properties}

The thermal expansion and tensile properties of the pure and graphite flakes loaded PVDF composites have been tested and the results are summarized in the Table 1. The results indicate that the coefficient of thermal expansion (CTE) as well as tensile strength of the composites decreases with increase in filler loading. Graphite has CTE of about $25 \mathrm{ppm} /{ }^{\circ} \mathrm{C}[30,31]$ while the pure PVDF has a high CTE of $145 \mathrm{ppm} /{ }^{\circ} \mathrm{C}$ and hence addition of graphite flakes decrease the CTE to $48 \mathrm{ppm} /{ }^{\circ} \mathrm{C}$ for $70 \mathrm{vol} \%$ of filler loading. A polymer ceramic composite has regions of tightly bounded polymer chains as well as loosely bound polymer chains near filler particles. The thermal expansion of polymer chains that are tightly bound to filler particles will be restricted 
while the expansion of the loosely bounded polymer chains remain affected. The number of loosely bounded polymer chains is reduced with increasing filler loading and results in the decrease of CTE [32]. For PVDF-Gp composites, tensile strength decreases from 41 to $5 \mathrm{MPa}$ with increase in filler loading from 0 to 70 vol\%. This decrease may be due to the poor filler matrix interface, porosity and hydrophilic nature of the filler [33, 34]. At high filler loading, the interface volume increases resulting in more filler-filler interactions that weakens the filler matrix interface leading to poor tensile properties. However, PVDF-Gp composite exhibits a tensile strength of $5 \mathrm{MPa}$ even at its higher filler loadings of $70 \mathrm{vol} \%$.

\subsection{EMI shielding effectiveness (EMI SE)}

EMI shielding effectiveness is the measure of electromagnetic energy shielded by a material. It refers to the logarithm of the ratio of incident power to that of transmitted power. The total shielding effect $(\mathrm{SE})$ is the sum of the net shielding by reflection $\left(\mathrm{SE}_{\mathrm{R}}\right)$ and absorption $\left(\mathrm{SE}_{\mathrm{A}}\right)$ and is obtained from the experimental scattering parameters as

$\mathrm{SE}_{\mathrm{A}}=-10 \log \left[\left(\mathrm{S}_{21}\right)^{2} /\left(1-\mathrm{S}_{11}{ }^{2}\right)\right]$

$\mathrm{SE}_{\mathrm{R}}=-10 \log \left(1-\mathrm{S}_{11}{ }^{2}\right)$

$\mathrm{EMI} \mathrm{SE}=\mathrm{SE}_{\mathrm{R}}+\mathrm{SE}_{\mathrm{A}}$ where $S_{11}$ and $S_{21}$ are the magnitude of the scattering parameters [35, 36].

Figure 3 (a) represents the total EMI shielding effectiveness of PVDF-Gp composites as a function of filler loading in the frequency range of 8.2-18 GHz. As expected, the EMI SE increases with filler loadings and exhibits good EMI shielding effectiveness at higher concentration. The PVDF-Gp composite with 70 vol\% Gp exhibits 55-57 dB in the measured frequency range. The EMI SE of pure PVDF is very low indicating that it is transparent to EM radiation, which corresponds to its poor conductivity value. The average distance between the filler particles decreases with increase in filler loading, which in turn increases the conductive networks in the polymer matrix resulting in the enhancement of shielding effectiveness. The EMI SE increases from $0.4 \mathrm{~dB}$ to $56 \mathrm{~dB}$ with increasing filler concentration from 0 to $70 \mathrm{vol} \%$ at 15 GHz. The composites have excellent EMI shielding efficiency in the measured frequency range. The accepted level of EMI SE needed for many practical applications is about $20 \mathrm{~dB}$. Hence about 40 vol\% of graphite flake filler in PVDF is only needed to attain the required shielding 
effectiveness with remarkable flexibility and tensile strength. The flake like morphology as well as smaller particle size of the graphite filler provide conductive pathways in the polymer matrix, which results in efficient EMI shielding.

\subsubsection{Shielding mechanism}

Mechanism of shielding is very important as it determines the shielding applications. EMI attenuated mainly by reflection and absorption. The $\mathrm{SE}_{\mathrm{R}}$ and $\mathrm{SE}_{\mathrm{A}}$ of PVDF-Gp composite are shown in the figure 3 (b) and (c) respectively. The results indicate that both $S_{R}$ and $S E_{A}$ of PVDF-Gp composite enhances with increasing filler loading. The $S E_{R}$ as well as $S E_{A}$ are function of conductivity that in turn leads to the increase. A comparison of EMI SE, SER and $\mathrm{SE}_{\mathrm{A}}$ of PVDF-Gp composites indicate that major contribution to the EMI SE comes from the $\mathrm{SE}_{\mathrm{A}}$ in the investigated frequency ranges. For example, $\mathrm{SE}_{\mathrm{R}}$ is $19-17 \mathrm{~dB}$ compared to $\mathrm{SE}_{\mathrm{A}}$ of 36$40 \mathrm{~dB}$ giving an overall EMI SE 55-57 dB for PVDF-70 Gp composite in the 8.2-18 GHz frequency range. Similar absorption dominated shielding mechanism were also reported for carbon based polymer composites [10]. For graphene film based EMI shielding materials, the $\mathrm{SE}_{\mathrm{R}}$ is observed to be much higher than the $\mathrm{SE}_{\mathrm{A}}$. These results were different from the graphene based materials with larger thickness where absorption becomes the dominant mechanism [4,13, 37]. This indicates that the sample thickness influences the shielding mechanism and thicker samples give higher absorption shielding. In addition to this, the two dimensional structure of these fillers also enhances the $\mathrm{SE}_{\mathrm{A}}$ as discussed earlier [9,12]. For these composites, the $\mathrm{SE}_{\mathrm{A}}$ increases while $\mathrm{SE}_{\mathrm{R}}$ decreases with frequency [21]. Hence, the increase in conductivity, frequency and thickness would lead to the increase in the $\mathrm{SE}_{\mathrm{A}}[4]$. Thus the $\mathrm{SE}_{\mathrm{A}}$ dominance in the PVDF-Gp composites are mainly due to the high measured frequency range, thickness of the sample $(1 \mathrm{~mm})$ and the layered morphology of the fillers. A schematic representation shown in figure 4 clearly demonstrates the absorption dominated EMI shielding mechanism in PVDF-Gp composite. These composites can find applications as absorbing shielding materials, which requires high absorption. The relationship of shielding efficiency with skin depth, electrical conductivity and shielding thickness are important in the design and applications of EMI shielding material.

\subsubsection{Electrical conductivity}


The variation of DC conductivity of PVDF-Gp composites with filler loading is shown in Table 1. A transition from the insulator to conductor is observed with increase in Gp loading in the PVDF matrix. These composites exhibit DC conductivity in the range of $10^{2} \mathrm{~S} / \mathrm{m}$ when the filler loading is more than 60 vol\%. Conducting nature of $\mathrm{Gp}$ fillers that built more and more conductive networks with increasing filler concentration within the polymer matrix may be responsible for the increase in the conductivity.

The AC conductivity of the composite can be obtained from imaginary part of permittivity $(\varepsilon ")$ and frequency as $\sigma(\mathrm{S} / \mathrm{m})=2 \pi f \varepsilon_{0} \varepsilon^{\prime \prime}$, where $\mathrm{f}$ is the frequency and $\varepsilon_{0}$ is permittivity of free space equal to $8.854 \times 10^{-12} \mathrm{~F} / \mathrm{m}$ [10]. Figure 5 (a) depicts the AC conductivity of the PVDF-Gp composites as a function of frequency as well as filler loading. There is an increase in the AC conductivity with filler loading as well as with frequency for both composites similar to the EMI SE. The increase in the filler loading built more and more conducting pathways in the polymer matrix, which leads to the hopping of electrons and hence contributes to the increased conductivity. The conductivity of these composites also increases with frequency as expected [38]. Thus high conductivity of these composites as evident from the DC and AC conductivity measurement is also one of the reasons for the good shielding properties.

\subsubsection{Skin depth}

Skin depth is the depth at which the electromagnetic field value drops to $1 / \mathrm{e}$ of the incident value and is given as $(\pi f \mu \sigma)^{-1 / 2}$, where $f$ is the frequency, $\mu$ is the magnetic permeability $=\mu_{0} \mu_{\mathrm{r}}, \mu_{\mathrm{r}}$ is the relative permeability, $\mu_{0}=4 \times 10^{-7} \mathrm{H} / \mathrm{m}$ and $\sigma$ is the conductivity in $\mathrm{S} / \mathrm{m}$ [21]. The skin depth of PVDF-Gp composites shows a reverse trend compared to that of conductivity as it decreases with filler loading as well as with frequency and is evident from figure 5 (b). The pure PVDF skin depth varied from $25 \times 10^{-3}$ to $12 \times 10^{-3} \mathrm{~m}$ at the frequency range of $8.2-18 \mathrm{GHz}$. The skin depth of PVDF-70 Gp composite is $0.3 \times 10^{-3} \mathrm{~m}$ at a frequency of $15 \mathrm{GHz}$. It decreases from $0.6 \times 10^{-3}$ to $0.3 \times 10^{-3} \mathrm{~m}$ for PVDF-70 Gp composite in frequency range of $8.2-18 \mathrm{GHz}$. All composites used in the present study have uniform thickness of $1 \mathrm{~mm}$ as given in the experimental section. Especially at higher filler loadings, the skin depths of the composites are less than the shielding thickness of $1 \mathrm{~mm}$. This decreased skin depth is due to the enhanced 
conductivity of these composites that is clear from Table 1, figure 5 (a) and (b). Thus, these composites can provide efficient shielding of about $20 \mathrm{~dB}$ at a low sample thickness.

\subsubsection{Effect of thickness}

Figure 5 (c) shows the effect of shielding thickness on EMI SE of PVDF-70 Gp composite in the $\mathrm{X}$ and $\mathrm{Ku}$ band frequency range. It is evident from the figure that, the EMI SE increases from 35$37 \mathrm{~dB}$ to $90-93 \mathrm{~dB}$ in the frequency range 8.2-18 GHz with increase in PVDF-70 Gp composite thickness from 0.5 to $2 \mathrm{~mm}$. The variation of SER and SEA with frequency for varying thickness of PVDF-70 Gp composite is given in the figure 5 (d) and (e) respectively. From these figures, it is evident that the $\mathrm{SE}_{\mathrm{A}}$ increased considerably with thickness for both the composites as compared to $\mathrm{SE}_{\mathrm{R}}$. The contribution from $\mathrm{SE}_{\mathrm{R}}$ and $\mathrm{SE}_{\mathrm{A}}$ to the EMI SE of 35-37 dB is 14-12 and 21-25 dB respectively for PVDF-70 Gp composite of $0.5 \mathrm{~mm}$ thickness. For $2 \mathrm{~mm}$ thick PVDF70 Gp composite, the $\mathrm{SE}_{\mathrm{R}}$ is $27-25 \mathrm{~dB}$ and that of $\mathrm{SE}_{\mathrm{A}}$ is 63-68 dB resulting an EMI SE of 90-93 $\mathrm{dB}$ in the $\mathrm{X}$ and $\mathrm{Ku}$ band frequency range. This indicates that the $\mathrm{SE}_{\mathrm{A}}$ is greatly influenced by the thickness and is in agreement with earlier reports $[4,39]$. As the frequency increases, the $\mathrm{SE}_{R}$ slightly decreases whereas the $\mathrm{SE}_{\mathrm{A}}$ increases while the total EMI SE remains almost constant over the measured frequency range. The present results indicate that an efficient shielding can be obtained with a sample thickness of about $0.5 \mathrm{~mm}$ and the EMI SE can be varied by varying the sample thickness.

\subsubsection{Effect of conductive layer on EMI SE of PVDF-70 Gp composite}

In order to investigate the effect of conductive layer on the shielding properties of a shielding material, two approaches have been made. In the first case, a thin coating (about $10 \mathrm{~nm}$ ) of $\mathrm{Cu}$ or Pt metal is made on $1 \mathrm{~mm}$ thick PVDF-70 Gp composite by vacuum deposition (one side) and its schematic diagram is shown in the supporting information figure S1. Another approach is by stacking PVDF-30 vol\% nano Ag composite (PVDF-30 nAg) of varying thickness $(0.1,0.5,1$ $\mathrm{mm}$ ) over $1 \mathrm{~mm}$ thick PVDF-70 Gp composite (schematic diagram is shown in the supporting information figure $\mathrm{S} 2$ ).

\subsubsection{Cu and Pt coating}


It is found that the presence of conductive layer leads to the increase of $\mathrm{SE}_{\mathrm{R}}$ and $\mathrm{SE}_{\mathrm{A}}$ of the composite that in turn leads to increase in EMI SE. As a representative example, the variation of EMI SE, $\mathrm{SE}_{\mathrm{R}}, \mathrm{SE}_{\mathrm{A}}$ of $\mathrm{Cu}$ and Pt coated PVDF-70 Gp composite with frequency and filler loading is given in figure 6 (a), (b) and (c) respectively. It is clear from figure 6 (a) that the average EMI SE increases from 56 to $73 \mathrm{~dB}$ with $\mathrm{Cu}$ coating and to $64 \mathrm{~dB}$ with Pt coating for the same frequency range. The high shielding value of $\mathrm{Cu}$ coated composite may be due to the slightly higher conductivity of the $\mathrm{Cu}$ as compared to Pt. The increase in the EMI SE by metallic coating can corresponds to the reflection of the EM wave into the composite by this metallic layer, which cause additional attenuation by absorption, and reflection [40]. The increase in EMI $\mathrm{SE}$ is also evident in the $\mathrm{SE}_{\mathrm{A}}$ and $\mathrm{SE}_{\mathrm{R}}$ value of the metal coated composite. The dominant shielding mechanism as well as frequency dependence of EMI SE, SER and $\mathrm{SE}_{\mathrm{A}}$ of metal coated composite is similar to that of PVDF-70 Gp composite. This indicates that metallic coating results in enhancing the EMI shielding efficiency of a composite.

\subsubsection{Stacking of PVDF-30 nAg composite of varying thickness}

Figure 7 (a), (b) and (c) respectively represents the variation of EMI SE, SER, SEA of PVDF-30 nAg composite stacked PVDF-70 Gp composite in the frequency range of 8.2-18 GHz. PVDF$30 \mathrm{nAg}$ composite of $1 \mathrm{~mm}$ thickness exhibits average EMI SE of $45 \mathrm{~dB}$ with $\mathrm{SE}_{\mathrm{R}}$ of $15 \mathrm{~dB}$ and $\mathrm{SE}_{\mathrm{A}}$ of $30 \mathrm{~dB}$ in the frequency range 8.2-18 GHz. Average EMI SE of PVDF-70 Gp composite increases from 56 to $67 \mathrm{~dB}, 80$ and $94 \mathrm{~dB}$ for the increase in stacked sample thickness from 0 to $0.1,0.5$ and $1 \mathrm{~mm}$ respectively. This increase is due to the combined shielding effect of multilayer structure of PVDF-30 nAg and PVDF-70 Gp composites. The electromagnetic waves undergo attenuation in both layers and hence contribute to this large EMI SE value. The $\mathrm{SE}_{\mathrm{R}}$ and $\mathrm{SE}_{\mathrm{A}}$ also follows similar trend and increases with the thickness of the stack. The dominant shielding mechanism of this multilayer structure is absorption as it is the dominant shielding mechanism of both composites [41]. The EMI SE of multilayer structure remains almost uniform while $\mathrm{SE}_{\mathrm{A}}$ increases and $\mathrm{SE}_{\mathrm{R}}$ decreases with frequency in the measured range. Hence, another effective approach to improve EMI shielding property is by the presence of conductive layer.

\section{Conclusion}


Graphite fillers were added into PVDF matrix by solution mixing method followed by hot pressing to obtain effective EMI shielding materials in the frequency range of $8.2-18 \mathrm{GHz}$. Composite exhibit good EMI SE of above $50 \mathrm{~dB}$ with absorption as the dominant shielding mechanism. An increase in shielding thickness is found to increase the EMI shielding efficiency with a major enhancement in the contribution from absorption. The obtained composite can provide good shielding against electromagnetic radiation at a sample thickness of less than 0.5 $\mathrm{mm}$. Electrical conductivity together with skin depth, shielding thickness and presence of conductive layer on the shielding material were found to be important factors governing the EMI shielding mechanism as well as EMI shielding efficiency of the composite. The present results are useful for designing thin, lightweight graphite reinforced PVDF based EMI shield for various range of EMI shielding applications with less cost by carefully changing the studied parameters.

\section{References}

[1] Eswaraiah V, Sankaranarayanan V, Ramaprabhu S. Functionalized graphene-PVDF foam composites for EMI shielding. Macromol Mater Eng 2011;296:1-5.

[2] Joseph N, Singh SK, Sirugudu RK, Murthy VRK, Ananthakumar KS, Sebastian MT. Effect of silver incorporation in to PVDF-barium titanate composites for EMI shielding applications. Mater Res Bull 2013; 48: 1681-87.

[3] Changlei X, Jason Y, Sheldon QS, Ying Q, Liping C, Felix WH, Han R, Xu Nie, Hualiang Z. Natural fiber and aluminum sheet hybrid composites for high electromagnetic interference shielding performance. Composites Part B 2017;114:12127.

[4] Wei LS, Mao SC, Ming ML, Song B, Chan YW, Jia L, Jie Y, Li ZF. Flexible graphene/polymer composite films in sandwich structures for effective electromagnetic interference shielding. Carbon 2014; 66: 67-76.

[5] Qiu Y, Guo F, Hurt RH, Kulaots I. Explosive thermal reduction of graphene oxide-based materials: mechanism and safety implications. Carbon 2014; 72:215-23.

[6] Pritom JB, Nitin M, Praveen CR, Kishore, Giridhar M. Poly(vinyl butyral) polyaniline-magnetically functionalized fly ash cenosphere composite film for electromagnetic interference shielding. Composites Part B 2016; 106: 224-33. 
[7] Changlei X, Kaili W, Youming D, Shifeng Z, Sheldon QS, Liping C, Han R, Hualiang Z, Jianzhang L. Dual-functional natural-fiber reinforced composites by incorporating magnetite. Composites Part B 2016;93:221-228.

[8] Xingmin L, Xiaowei Y, Luo K, Quang L, Ye L, Wenyan D, Litong Z, Laifei C.

Fabrication and electromagnetic interference shielding effectiveness of carbon nanotube reinforced carbon fiber/pyrolytic carbon composites. Carbon 2014;68:501-10.

[9] Guang SW, Xiao JZ, Yun ZW, Shuai H, Lin G, Mao SC. Polymer composites with enhanced wave absorption properties based on modified graphite and polyvinylidene fluoride. J Mater Chem A 2013;1:7031-36.

[10] Mohammed HA, Walaa HS, Uttandaraman S. EMI shielding effectiveness of carbon based nanostructured polymeric materials: A comparative study. Carbon 2013;60:14656.

[11] Mehdi M, Mohammad A, Uttandaraman S, Simon P. The electrical conductivity and electromagnetic interference shielding of injection molded multi-walled carbon nanotube/polystyrene composites. Carbon 2012;50:1455-64.

[12] Zongping C, Chuan X, Chaoqun M, Wencai R, Hui MC. Light weight and flexibile graphene foam composites for high performance electromagnetic interference shielding. Adv Mater 2013;25:1296-300.

[13] Ding XY, Peng GR, Huan P, Qiang F, Ming B Y, Zhong ML. Efficient electromagnetic interference shielding of light weight graphene/polystyrene composite. J Mater Chem 2012;22:18772-74.

[14] Praveen S, Veena C, Sood KN, Dhawn SK. Electromagnetic interfence shielding behavior of polyaniline/graphite composites prepared by in situ emulsion pathway. $\mathrm{J}$ Appl Polym Sci 2008;113:3146-55.

[15] Subhadip M, Sayan G, Poushali D, Dipak K, Narayan CD. Low percolation threshold and electromagnetic shielding effectiveness of nano-structured carbon based ethylene methyl acrylate nanocomposites. Composites Part B 2017; doi: 10.1016/j.compositesb.2017.03.022.

[16] Chun-Yu C, Nen-Wen P, Yih-Ming L, Sheng-Yao H, Chia-Hung W, Ming-Der G, Yan-Jhang G, Yu-Chieh C. Remarkable microwave absorption performance of 
graphene at a very low loading ratio. Composites Part B 2017;114:395-403.

[17] Hui T, Xian J, Biao W, Shiyu L, Zhicheng J, Xiangnan C, Weiqiang L, Weidong H, Wei T, Yufeng W, Yuqi G, Tong C, Gang L. $\mathrm{Fe}_{3} \mathrm{C} /$ helical carbon nanotube hybrid: Facile synthesis and spin-induced enhancement in microwave-absorbing properties. Composites Part B 2016;107:51-58.

[18] Subhadip M, Lalatendu N, Mostafizur R, Ali A, Tapan KC, Dipak K, Narayan CD, An effective strategy to enhance mechanical, electrical, and electromagnetic shielding effectiveness of chlorinated polyethylene-carbon nanofiber nanocomposites. Composites Part B 2017;109:155-69.

[19] Shyh-shin H. Tensile, electrical conductivity and EMI shielding properties of solid and foamed PBT/carbon fiber composites. Composites Part B 2016;98:1-8.

[20] Yoon-Ji Y, Kyong YR, Soo-Jin P. Electromagnetic interference shielding effectiveness of nickel-plated MWCNTs/high-density polyethylene composites. Composites Part B 2016;98:120-25.

[21] Chung DDL. Review electromagnetic interference shielding effectiveness of carbon materials. Carbon 2001;39:279-85.

[22] Ahmed A Al-G, Omar A Al-H, Falleh R Al-S, Nikolay D, Petrunka M, Gabriela A, Nikolay A. Conductive carbon black/magnetite hybrid fillers in microwave absorbing composites based on natural rubber. Composites Part B 2016;96:231-41.

[23] Jude AO, Miskolczi N, Nagy T, Lipoczi G. Recovery of glass fibre and carbon fibres from reinforced thermosets by batch pyrolysis and investigation of fibre re-using as reinforcement in LDPE matrix. Composites Part B 2016;91:154-61.

[24] Ahmed A Al-G, Attieh A Al-G, Yusuf Al-T , Yakuphanoglu F, Farid El-T. Electromagnetic shielding properties of graphene/acrylonitrile butadiene rubber nanocomposites for portable and flexible electronic devices. Composites Part B 2016;88:212-19.

[25] Kuester S, Merlini C, Barra GMO, Ferreira Jr. JC, Lucas A, de Souza AC, Soares BG. Processing and characterization of conductive composites based on poly(styrene-bethylene-ran-butylene-b-styrene) (SEBS) and carbon additives: A comparative study of expanded graphite and carbon black. Composites Part B 2016;84:236-47. 
[26] Lin J-H, Lin Z-I, Pan Y-J, Huang C-L, Chen C-K, Lou C-W. Polymer composites made of multi-walled carbon nanotubes and graphene nano-sheets: Effects of sandwich structures on their electromagnetic interference shielding effectiveness, Compos Part BEng 2016;89:424-31.

[27] Fuan H, Sienting L, Helen LC, Jintu F. High dielectric permittivity and low percolation threshold in nanocomposites based on poly(vinylidene fluoride) and exfoliated graphite nanoplatelets. Adv Mater 2009;21:710-15.

[28] Li L, Mingqiu Z, Minzhi R, Wenhong R. Studies on the transformation process of PVDF from $\alpha$ to $\beta$ phase by stretching. RSC Adv 2014;4:3938-43.

[29] Farheen NS, Sasikala R, Jayakumar OD, Rao R, Betty CA, Anand C, Kadam RM, Jagannath, Bharadwaj SR, Ajayan V, Tyagi AK. Photocatalytic hydrogen generation from water using a hybrid of graphene nanoplatelets and self doped TiO2-Pd. RSC Adv 2014;4:13469-76.

[30] Pierson HO. Handbook of Carbon, Graphite, Diamond, and Fullerenes: Properties, Processing, and Applications (Noyes Publications, Park Ridge, NJ, 1993) pp. 59-60.

[31] Kin L, Li S. Interfacial characteristics of a carbon nanotube-polystyrene composite system. Appl Phys Lett 2001;79:4225-27.

[32] Goyal RK, Tiwari AN, Mulik UP, Negi YS. Novel high performance $\mathrm{Al}_{2} \mathrm{O}_{3} /$ poly(ether ether ketone) nanocomposites for electronics applications. Comp Sci Tech 2007;67:1802-12.

[33] Rusu M, Sofian N, Rusu D. Mechanical and thermal properties of zinc powder filled high density polyethylene composites. Polym Test 2001;20:409-17.

[34] Murali KP, Rajesh S, Prakash O, Kulkarni AR Ratheesh R. Preparation and properties of silica filled ptfe flexible laminates for microwave circuit applications. Composites: Part A 2009; 40: 1179-85.

[35] Annapurna D, Sisir KD. Microwave Engineering (Tata McGraw Hill, India, 2009).

[36] Joseph N, Sebastian M T. Electromagnetic interference shielding nature of PVDFcarbonyl iron composites. Mater Lett 2013;90:64-67.

[37] Zhang HB, Yan Q, Zheng WG, He ZX, Yu ZZ. Tough graphene polymer microcellular foams for electromagnetic interference shielding. ACS Appl Mater Interfaces 
2011;3:918-24.

[38] Choi HW, Heo YW, Lee JH, Kim JJ, Lee HY, Park ET, Chung YK. Effects of $\mathrm{BaTiO}_{3}$ on dielectric behavior of $\mathrm{BaTiO}_{3}-\mathrm{Ni}$ polymethylmethacrylate composites. Appl Phys Lett 2006;89:132910-12.

[39] Joseph N, Chameswary J, Sebastian MT. Electromagnetic interference shielding properties of butyl rubber-single walled carbon nanotube composites. Comp Sci Tech 2014; 101:139-44.

[40] Huo J, Wang L, Yu H. Polymeric nanocomposites for electromagnetic wave absorption. J Mater Sci 2009;44:3917-27.

[41] Chen M, Zhu Y, Pan Y, Kou H, Xu H, Guo J. Gradient multilayer structural design of $\mathrm{CNTs} / \mathrm{SiO}_{2}$ composites for improving microwave absorbing properties. Mater Des 2011; $32: 3013-16$.

\section{Tables}

Table 1 representing the DC conductivity, thermal and mechanical properties

(a) PVDF-Gp composite

\begin{tabular}{cccc}
\hline Composite & $\begin{array}{c}\text { DC conductivity } \\
\mathbf{( S / m )}\end{array}$ & $\left.\begin{array}{c}\text { Coefficient of } \\
\text { thermal } \\
\text { expansion(ppm/ }\end{array}{ }^{\circ} \mathbf{C}\right)$ & $\begin{array}{c}\text { Tensile } \\
\text { strength }(\mathbf{M P a})\end{array}$ \\
\hline 0 & $10^{-14}$ & 145 & 41 \\
10 & $9.8 \times 10^{-5}$ & 123 & 36 \\
20 & $5.0 \times 10^{-2}$ & 118 & 30 \\
30 & $2.0 \times 10^{-1}$ & 107 & 25 \\
40 & $5.0 \times 10^{0}$ & 95 & 20 \\
50 & $10.0 \times 10^{1}$ & 81 & 16 \\
60 & $8.0 \times 10^{2}$ & 65 & 10 \\
70 & $14.4 \times 10^{2}$ & 48 & 5 \\
\hline
\end{tabular}


Figures

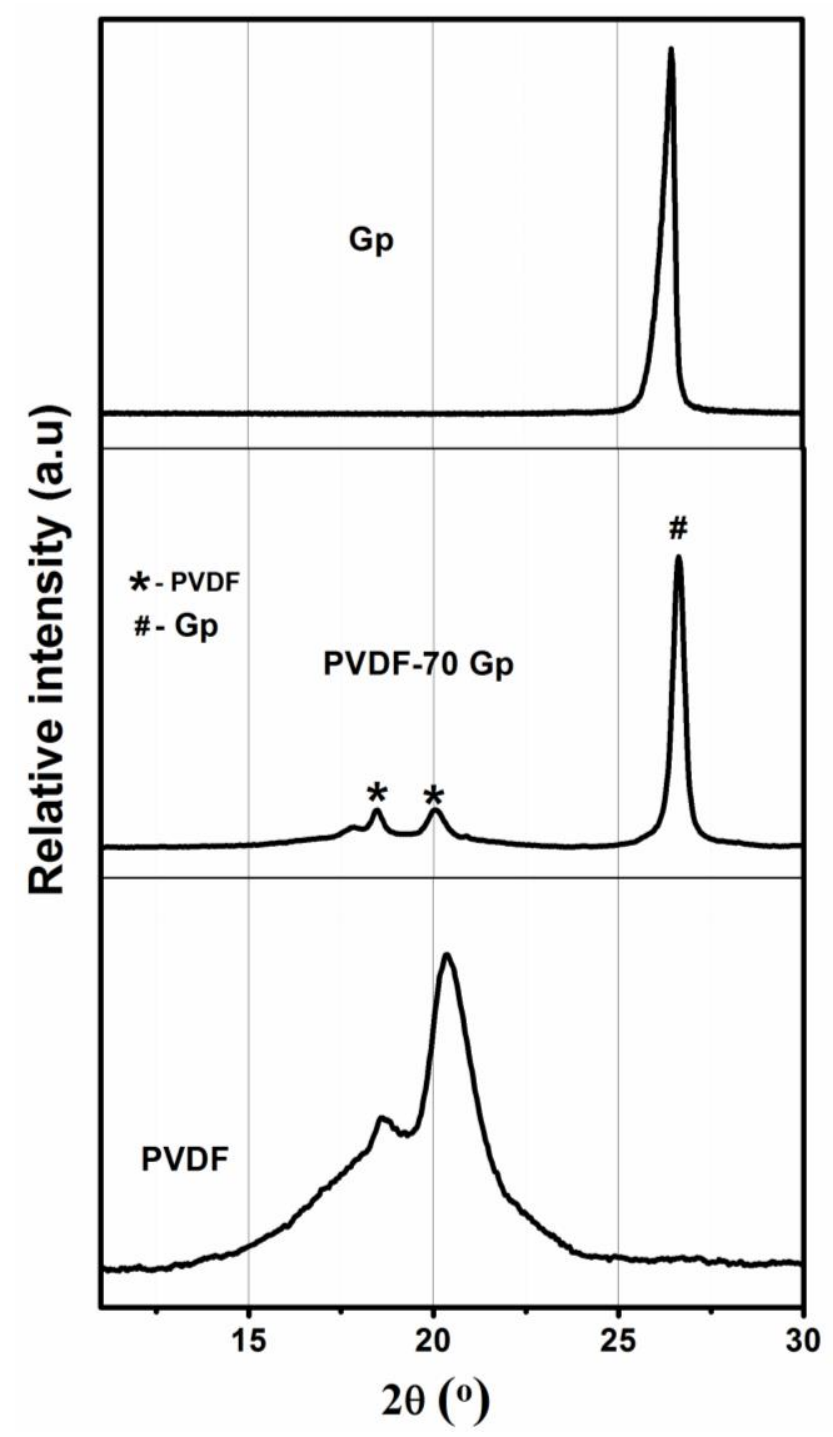

Figure 1 XRD pattern of PVDF, PVDF-70 Gp composite and Gp filler. 


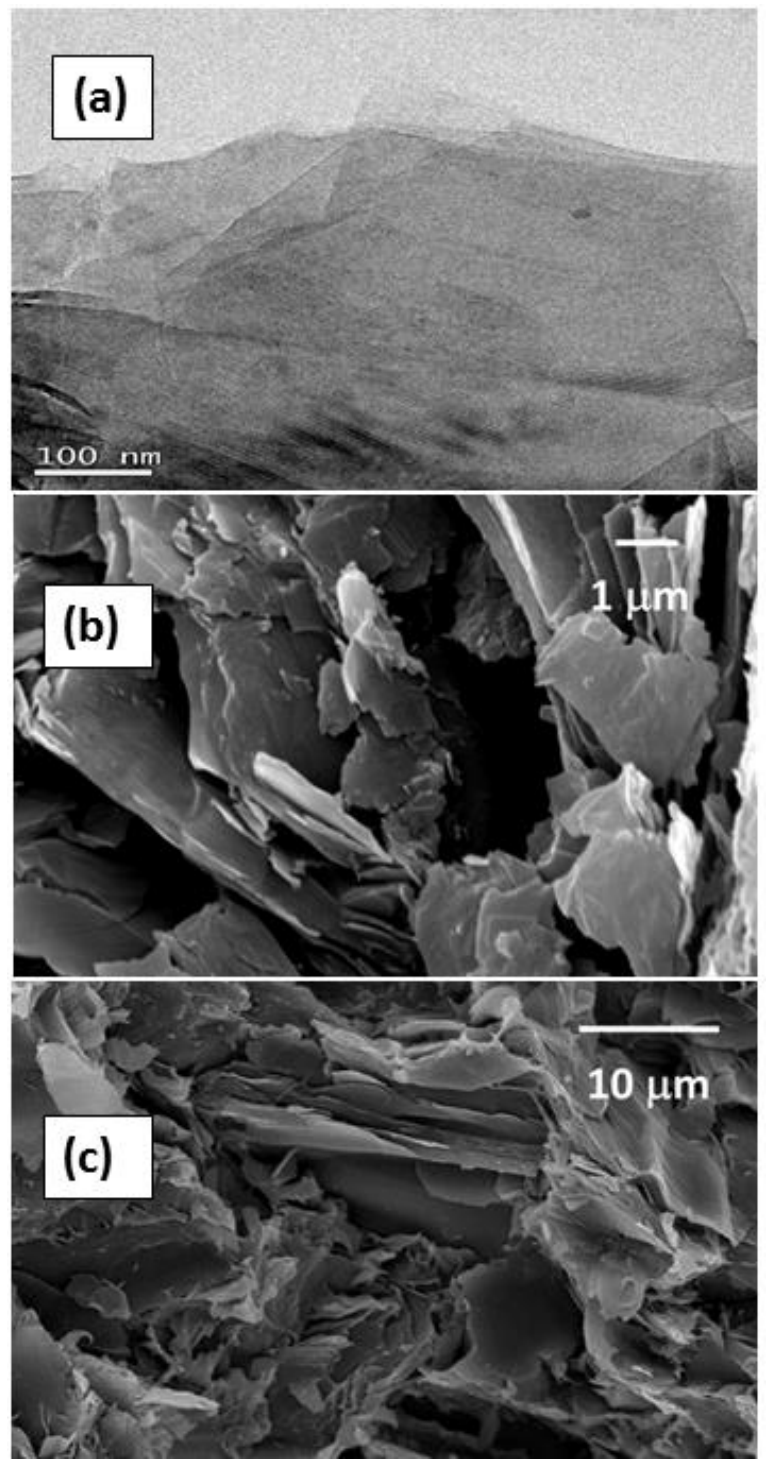

Figure 2 TEM images of (a) Gp powder, SEM images of (b) Gp powders and (c) fractogram of PVDF-70 Gp composite. 


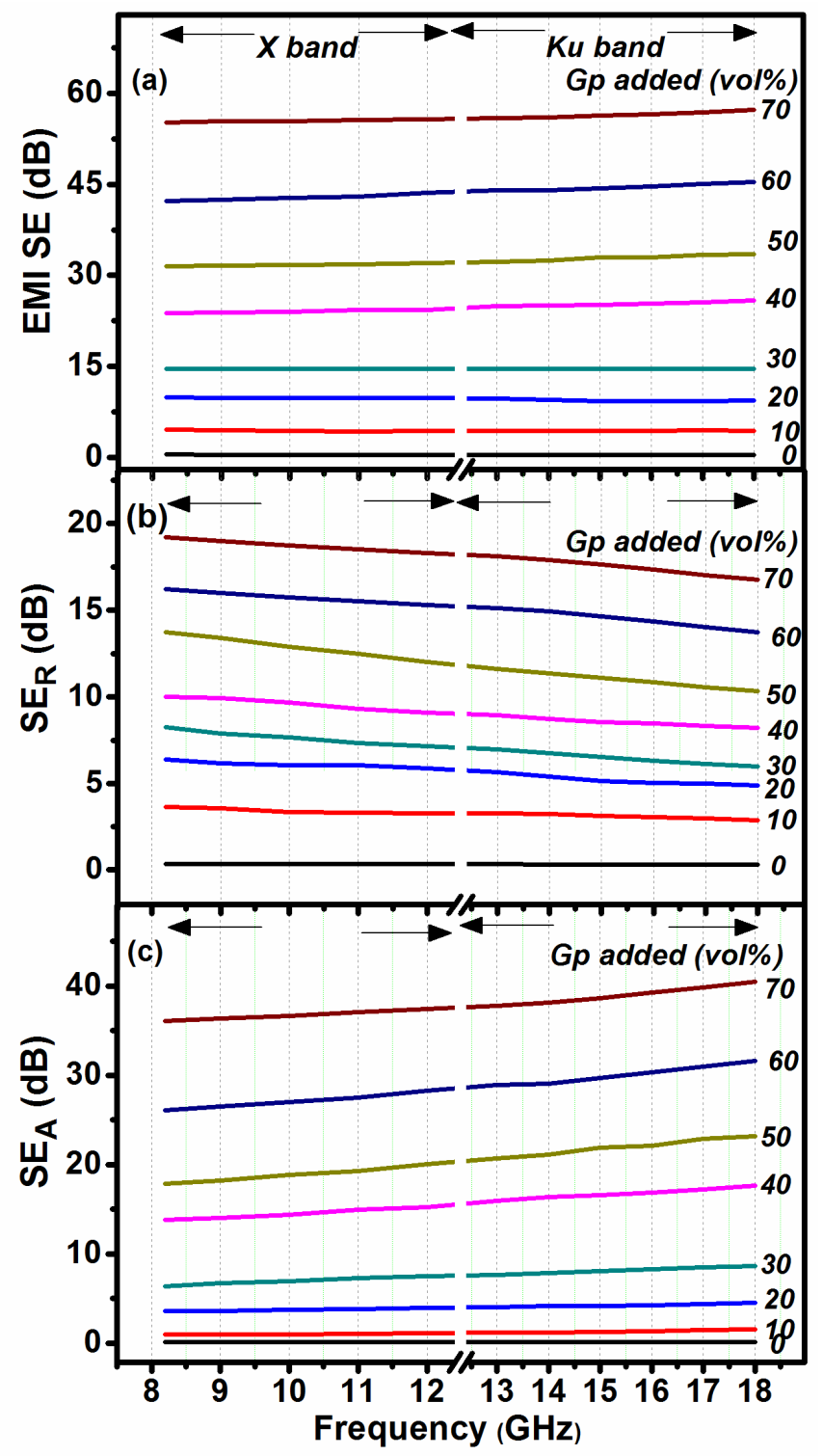

Figure 3 (a) EMI SE, (b) $\mathrm{SE}_{\mathrm{R}}$ and (c) $\mathrm{SE}_{\mathrm{A}}$ of PVDF-Gp composite in the frequency range of 8.2$18 \mathrm{GHz}$. 


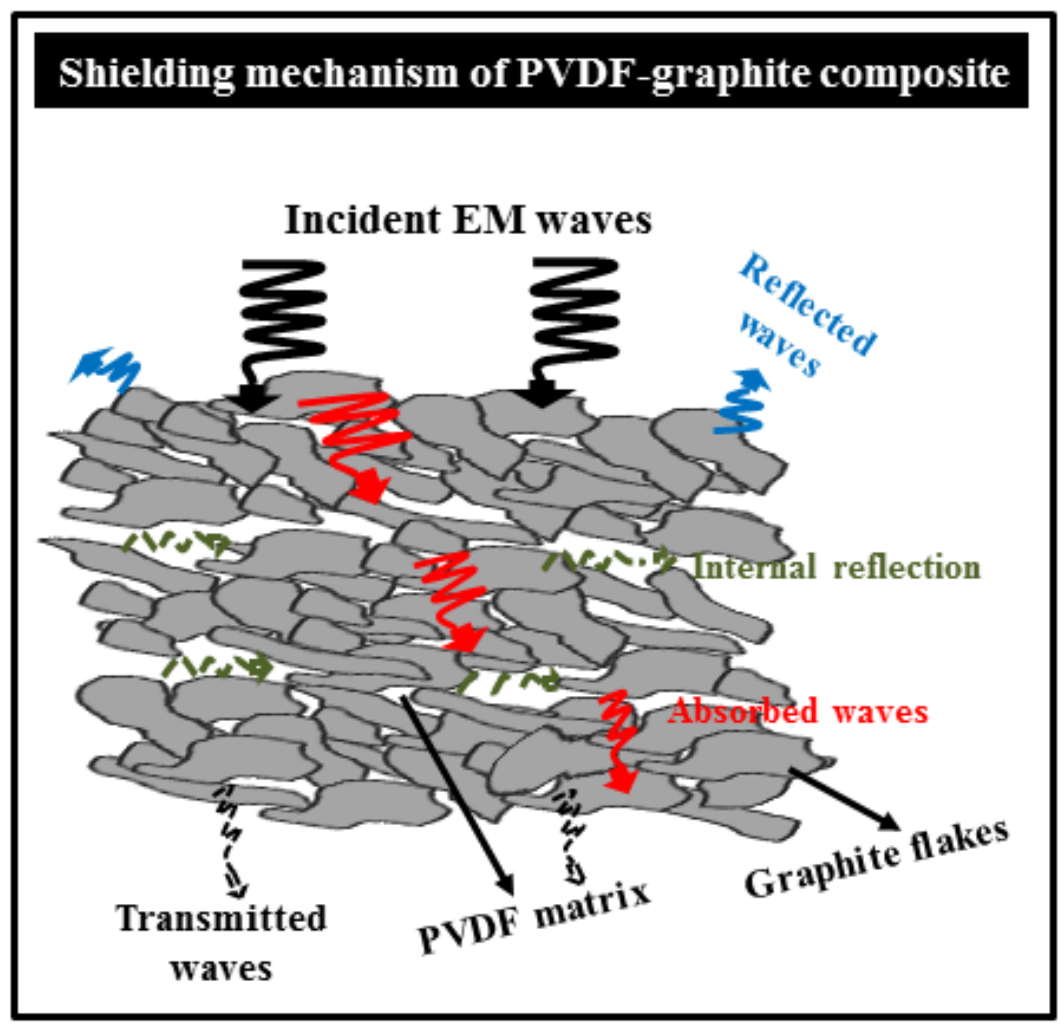

Figure 4 Schematic representation of EMI shielding mechanism in PVDF-Gp composite. 

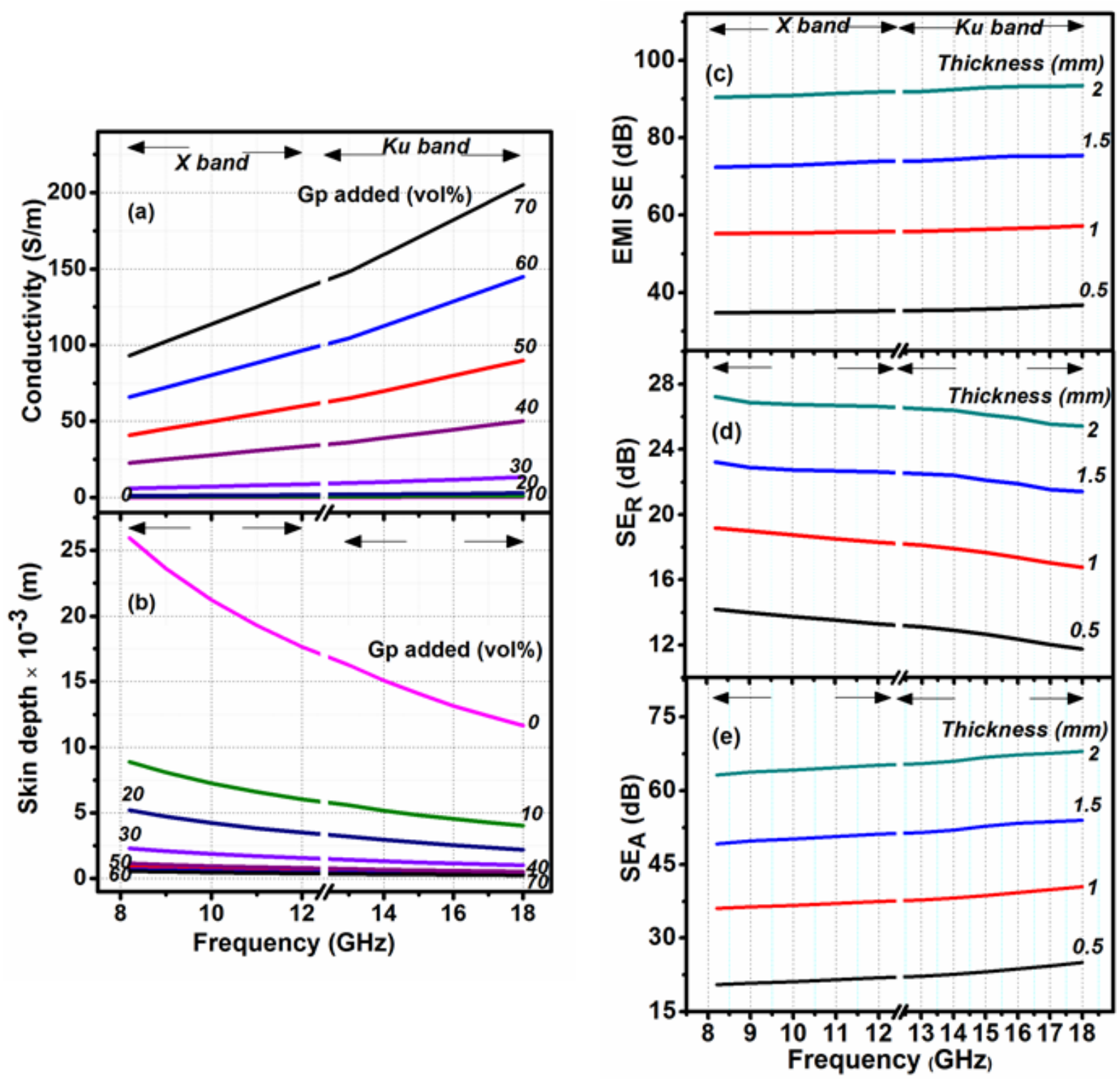

Figure 5 (a) AC conductivity, (b) skin depth of PVDF-70 Gp composite and variation of (c) EMI $\mathrm{SE}$, (d) $\mathrm{SE}_{\mathrm{R}}$ and (e) $\mathrm{SE}_{\mathrm{A}}$ thickness in the frequency range of 8.2-18 GHz. 

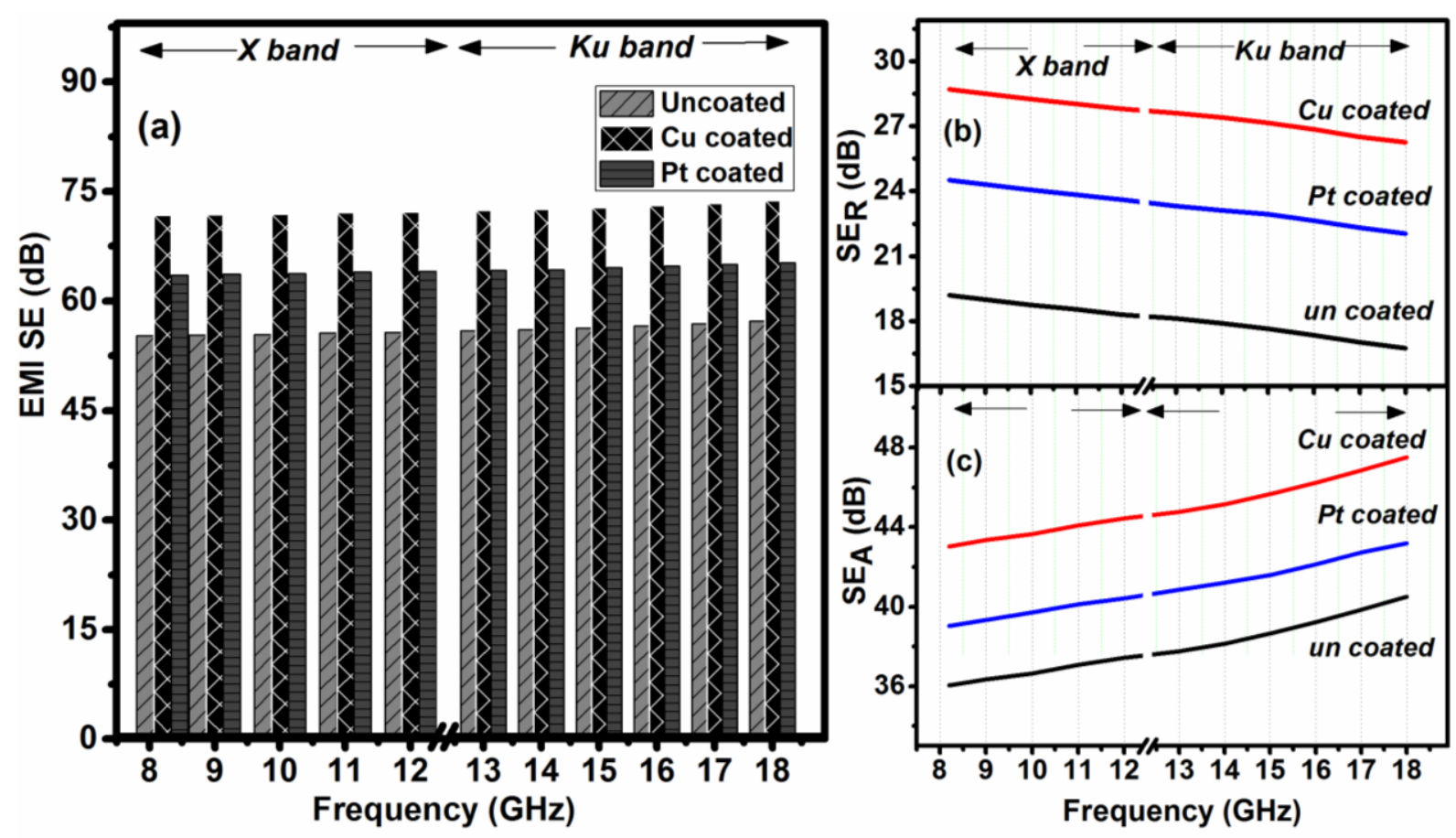

Figure 6 Variation of (a) EMI SE (b) $\mathrm{SE}_{\mathrm{R}}$ (c) $\mathrm{SE}_{\mathrm{A}}$ of PVDF-70 Gp with different metallic coating
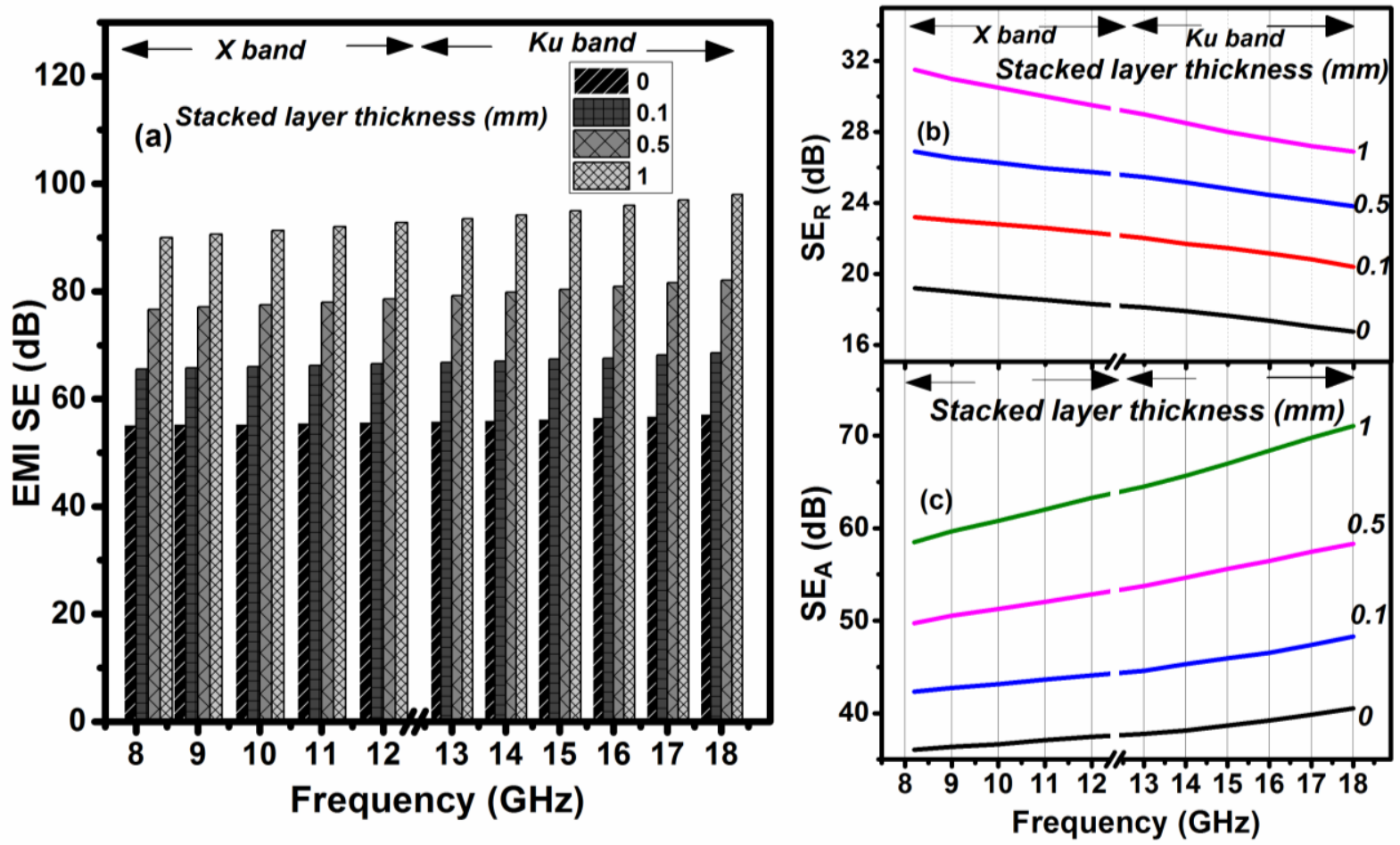

Figure 7 Variation of (a) EMI SE (b) SER (c) SE A of PVDF-70 Gp with different stacked thickness of PVDF-30 nAg composite. 


\section{Graphite reinforced polyvinylidene fluoride composite an efficient and sustainable solution for electromagnetic pollution}

Nina Joseph ${ }^{\mathrm{a}}$, Jobin Varghese ${ }^{\mathrm{a}, \mathrm{b}}$ and Mailadil Thomas Sebastian ${ }^{\mathrm{a}, \mathrm{b} *}$
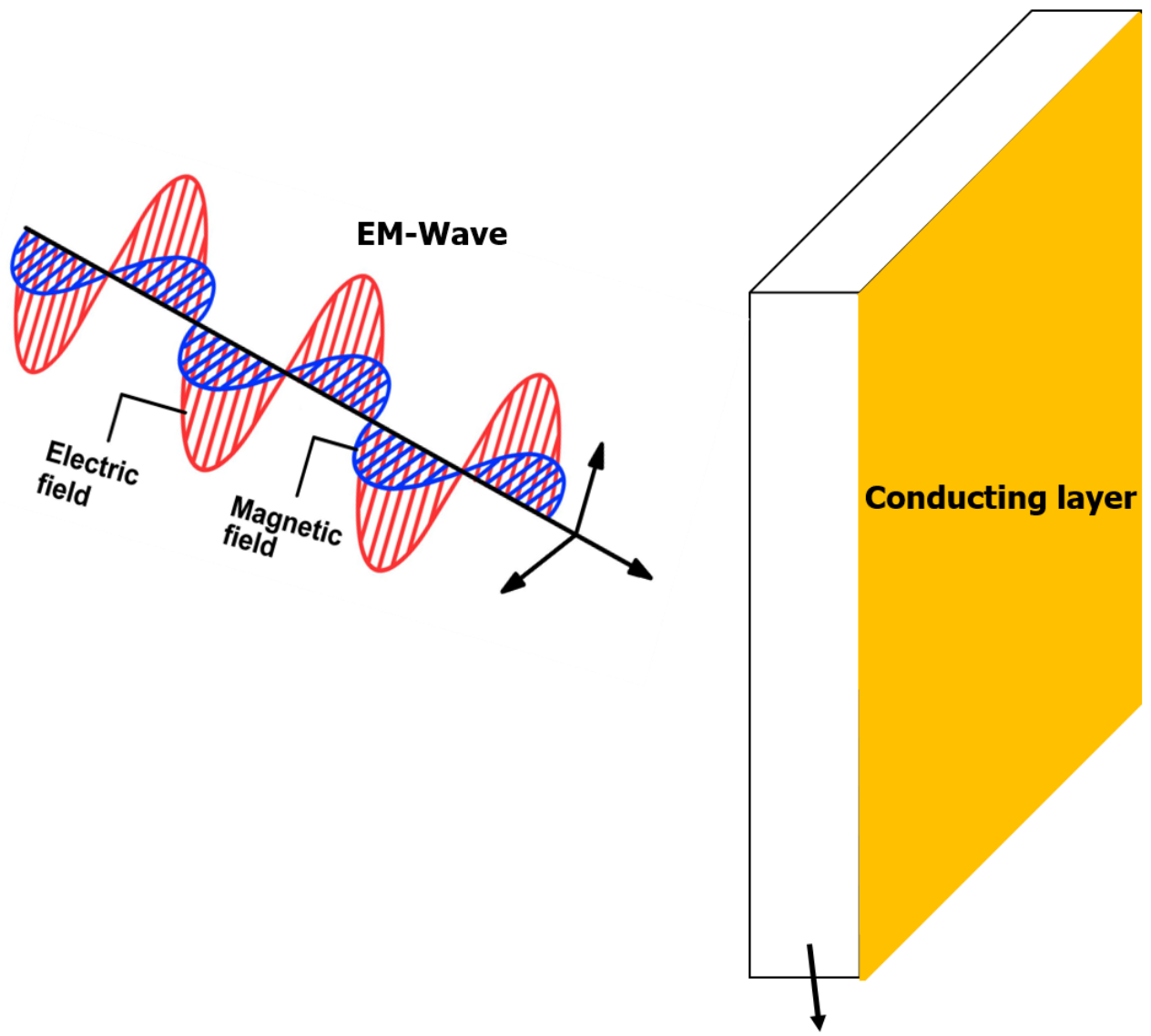

PVDF-70 Gp Composite

Figure S1 Schematic representation of single side metallic coating on PVDF-

70 Gp Composite 


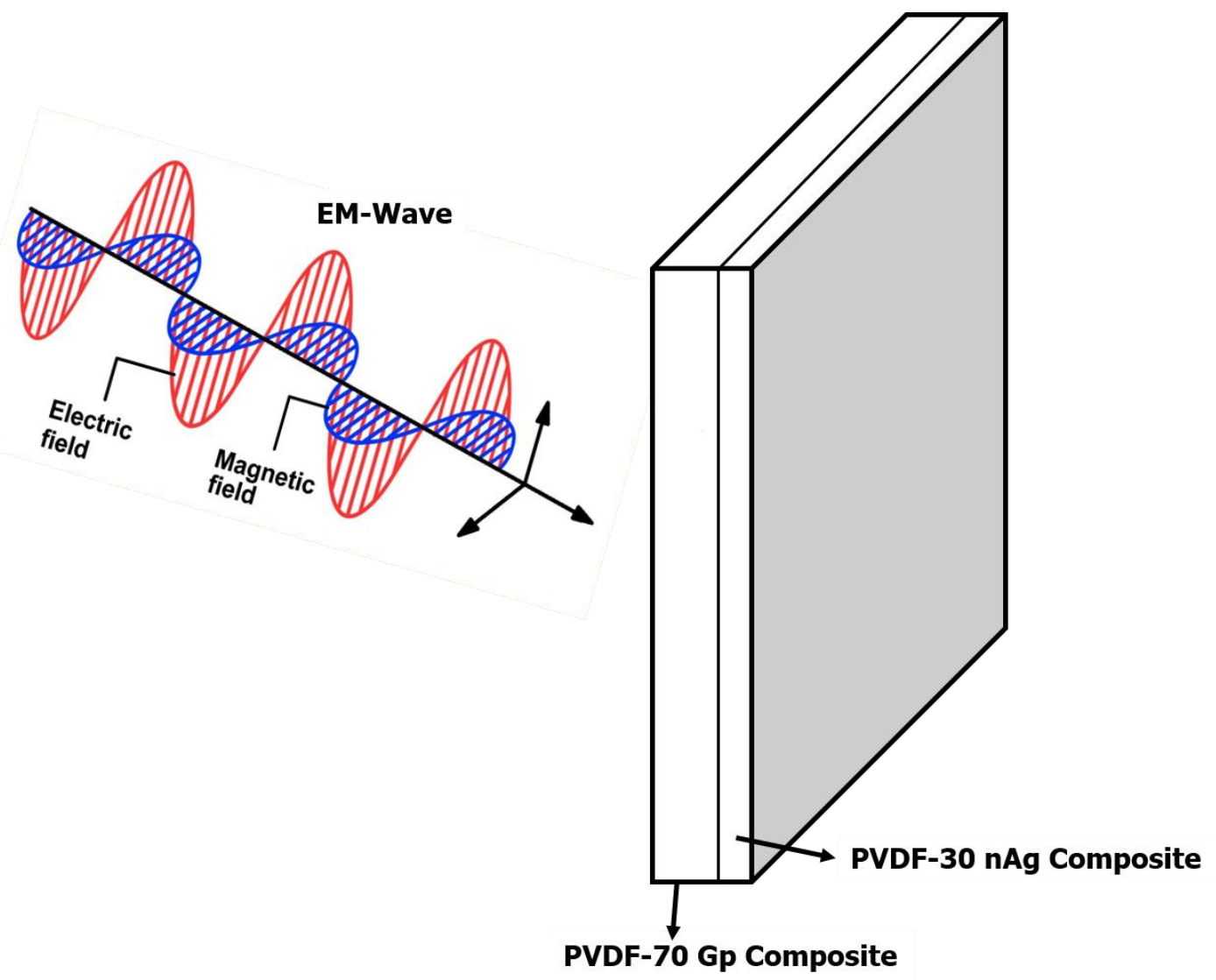

Figure S2 Schematic representation of multilayer stacking on PVDF-70 Gp Composite 